\title{
Tumores hepáticos primitivos (THP) en niños. Presentación de 7 casos
}

Los tumores hepáticos primitivos (THP) son raros en los niños. Se les divide en benignos y malignos.

El adenoma hepático es un tumor benigno caracterizado por proliferación de células hepáticas o conductos biliares. Los rangos de DNA diploide $^{22}$ en las células de este tipo tumoral tienen distribución similar a las células hepáticas normales. Ha recibido múltiples nombres ${ }^{14}$.

Los THP derivados del mesodermo; hemangioma, hemangioendotelioma, son algo más frecuentes en pediatría ${ }^{6-8-12-23}$. Adenomas y hemangiomas al crecer en forma rápida están expuestos a sufrir rupturas ${ }^{21}$ por aumento de la fragilidad capilar.

Los THP malignos ${ }^{15}$ se han relacionado con ciertas sustancias carcinógenas ${ }^{3}$. Presentan alto grado de mitosis ${ }^{22}$ y se caracterizan por su curso generalmente fatal. De utilidad diagnóstica en este tipo de tumor es la presencia de AlfaFeteproteína $^{2-9-19}$.

El objetivo de esta presentación es dar a conocer nuestra experiencia sobre 7 casos de tumores hepáticos entre los años 1969 y 1975.

\section{MATERIAL}

\section{CASO CLINICO ${ }^{\circ} 1$}

Ficha 275085: C. V. J. lactante de 1 año 6 meses de edad. sexo masculino. Desde $\operatorname{los} 8$ meses de vida la madre le nota

* Jefe Servicio Anatomía Patológica, Hospital Luis Calvo.Mackenna.

** Médico Becado sss. Incorporación a la Sociedad

***Jefe del Servicio de Oncología, Hospital Luis Calvo Mackenna.

*** Servicio de Oncología, Hospital Luis Calvo Mackenna.

*****Jefe del Servicio de Cirugía, Hospital Luis Calvo Mackenna.
Dres. Juan J. Latorre L. *, Antonio Barrera**, Humberto del Pozo***, Victoria Beresi**** y Alfredo del RíbM.****.

el abdomen promitente y detención de la curva pondoestatural. Dos meses antes de su ingreso al Hospital Luis aton Mackenna (15-1-75), se compueba hígado a $Z \mathrm{~cm}$ y circulación colateral. Posteriormente consulta en Hepatología por hepatomegalia de $10 \mathrm{~cm}$. Con el diagnóstico clínico de tumor abdominal se le somete a la paratomia procediéndose a extirpar totalmente un tumor que comprometía el lóbulo izquierdo del hígado, redondeado, intensamente vascularizado (pesó $700 \mathrm{grs}$ ). No fue necesario realizar lobectomía. El análisis histopatológico fue efectuado por cuatro patólogos de diferentes servicios de Santiago, concluyendo todos en el diagnóstico de hepatoblastoma.

Exámenes complementarios postoperatorios: Hemograma con 4.100.000 hematies, Hemoglobina $11.1 \mathrm{gr} \%$, Hematocrito 34\%, Leucocitos 17.600 ( Eos 4, Seg. 53, Linfo 35, Mono. 7, C. Plasm. 1).

Plaquetas normales. VHS: $5 \mathrm{~mm}$.

Examen de orina: normal.

Alfafetoproteína positiva en 3 oportunidades.

Exploración hepática: Bilirrubina directa 0,12 mgr\%, Bilirrubina total $0,46 \mathrm{mgr} \%$. Fofatasa alcalina: $4,4 \mathrm{C}$. Colesterol: $207 \mathrm{mgr} \%$. Transaminasa pirúvica: $23 \mathrm{~L}, \mathrm{~K}$.

Antigeno Australia: negativo.

Hapatoglobina: $412 \mathrm{mgr} \%$.

Cintigrama hepático (14-1-75) con radionucleido In 113: en el extremo superior izquierdo se observa zona de 2 por $3 \mathrm{~cm}$ que concentra el radiocoloide en forma irregular. Resto del parénquima normal.

Inmunoglubulinas: IgG $256 \mathrm{U} / \mathrm{ml}$ (normal: 94-148); IgM $364 \mathrm{U} / \mathrm{ml}$ (normal: 62-166); IgA $102 \mathrm{U} / \mathrm{ml}$.

Complemento C-3 170 mgr\% (normal: 85-170)

Evolución: 11 dias después de su intervención se inició tratamiento con Vincristina $0,55 \mathrm{mgr}$ semanal y 5-F. L. 76 $\mathrm{mgr} /$ dia por 5 días. La segunda y tercera dosis de Vincristina fue de $0,88 \mathrm{mgr}$. En el $2^{\circ}$ ciclo de tratamiento (17-11-75) Vincristina $0,55 \mathrm{mgr}$ y $5-\mathrm{F}$. U. $80 \mathrm{mgr} / 24 \mathrm{hrs}$. por 3 días. Se completó este ciclo con 4 dosis de Vincristina. El recuento de leucocitos llegó a 4.400 , hemoglobina a 8.2 grs\% y hematocrito a $28 \%$.

El tercer ciclo de tratamiento se inició el 31-IIl-75 con las mismas drogas. El cintigrama hepático estaba dentro de límites normales y la alfafetoproteina persistía positiva.

Se inició el día $5-\mathrm{V}-75$ un $4^{\circ}$ ciclo con Vincristina 0,55 mgrs semanal y 5 -F.U. 80 mgrs $/ 24$ hrs. por 5 días. Recibió tres dosis de Vincristina, demostrándose un recuento de blancos de 3.300 , y anemia hipocroma. El estudio radiológico de tórax fue normal. 
El $5^{\circ}$ ciclo quimoterápico $(9-\mathrm{V} \mathrm{J}-7 \overline{5})$ no tuvo alteraciones significativas hematológicas.

El $6^{\circ}$ ciclo (14-VII-75) se caracterizó por su buena tolerancia. Cintigrama hepático normal. Radiografía de tórax normal. Exploración hepática normal.

Después de 8 meses de tratamiento se considera de buen pronóstico y se decide suspender la quimoterapia el 25.VIII75.

Luego de 11 meses de intervenido, el último control efectuado (25-XI-75) demostró un paciente en huenas condiciones generales.

\section{CASOCLINICON ${ }^{\circ} 2$}

Ficha 236268: R. R. G. P., preescolar de 3 años 5 meses de edad, sexo masculino. Ingresa al Hospital Calvo Mackenna et 22-VIII-72 por dolores abdominales de tipo cólico de 11 días de evolución; en los 3 últimos dias presenta vómitos.

Examen fisico: Buenas condiciones nutritivas, abdomen levemente abombado en su parte superior, con discreta circulación colateral. En hipocondrio derecho a $6 \mathrm{~cm}$ del reborde costal se palpa masa dura redondeada que compromete epigastrio, de superficie algo irregular, de límites netos e indolora. En el hipocondrio izquierdo se palpa masa dura a $4 \mathrm{~cm}$ bajo el reborde costal, de superficie irregular y límites netos.

Diagnóstico de ingreso: Hepatoesplenomegalia. ¿Tumor hepático? Evoluciona sin compromiso del estado general.

Exámenes complementarios: a) radiografia toracoabdominal: bazo algo aumentado de tamaño; b) reacción de hemaglutinación para hidatidosis: negativa; c) batería inmunológica: IgG $128 \mathrm{U} / \mathrm{ml}$, IgM $228 \mathrm{U} / \mathrm{ml}$, IgA $116 \mathrm{U} / \mathrm{ml}$ Haptoglobinas $170 \mathrm{mgrs} \%$. Antigeno Australia: negativo.

Intervención quirúrgica (24-viII-72): laparatomía transversa, en el higado se encuentran 2 grandes masas tumorales que ocupan todo el lóbulo y gran parte del derecho, dejando tejido sano en medio del tumor, de consistencia dura, no sangra al corte. Se tomó biopsia hepática y de ganglios del mesenterio.

Dagnóstico histopatológico: Carcinoma de células hepáticas tipo nodular (hepatoma).

Se inicia tratamiento con Vincristina $0,90 \mathrm{mgrs}$, Actinomicina D 250 gamas y Ciclofosfarnida $100 \mathrm{mgrs}$ E. V., dosis semanal.

Fallece a los 4 meses de intervenido (20-XII-72).

\section{CASO CLINICON $\mathrm{N}^{\circ} 3$}

Ficha 247572: P. P. O. Preescolar de 2 años de edad, sexo femenino. Buen estado nutritivo. Ingresó al Hospital Cal vo Mackenna el 10-v-73. Un día antes de su ingreso presenta fiebre, tos escasa, disnea quejumbrosa y meteorismo. Al examen físico presenta un peso de 13 kilos, disnea, aleteo nasal, retracción intercostal. Pulmones: disminución del murmullo vesicular basal bilateral, respiración soplante. Abdomen: abultado, tenso meteorizado, doloroso a la palpación, resistencia muscular en hemiabdomen derecho donde se palpa masa irregular, dolorosa, que ocupa epigastrio, hipocondrio y flanco derecho. Radioscopía revela opacidad lateral derecha del abdomen. Radiografia de tórax normal. No se auscultan ruidos hidroaéreos.

Se interviene el 11-v-73 con el diagnóstico de hematoma subcapsular hepático. ¿Invaginación intestinal? Al abrir peritoneo fluyen $160 \mathrm{cc}$ de sangre fresca, hígado aumentado de volumen a expensas del lóbulo derecho el que desciende hasta línea umbilical, sembrado de nódulos de 1 a $2 \mathrm{~cm}$ de diámetro y compromiso capsular con una zona ulcerada necrótica hemorrágica recubierta de epiplón. El proceso tumoral es inextirpable por lo cual se procede sólo a tomar muestra para biopsia.

El resultado de la biopsia es compatible con un carcinoma hepático primitivo

El postoperatorio se caracterizó por progresivo deterioro del estado general, edema maleolar y oligoanuria. El día 18-v-73 presenta evisceración de herida operatoria, la que se interviene, continuando posteriormente con ruidos hidroaéreos, resistencia muscular voluntaria y hepatomegalia a $14 \mathrm{~cm}$ bajo el reborde costal. El borde superior del hígado se percute en el tercer espacio intercostal.

Se inició tratamiento quimoterápico el día de su intervención, con Vincristina $0,84 \mathrm{mgrs}$ y Ciclofosfamida $112 \mathrm{mgrs}$ en dosis semanal. En la segunda semana se agrega Actinomicina I) 200 gamas.

Los controles sucesivos de glóbulos blancos, evidenciaron leucopenia sólo después de la cuarta cura. Recibió ampicilina, cloxacilina y gentamicina por infecciones intercurrentes. Durante toda sus evolución presentó fiebre de 37,3 y $38^{\circ} \mathrm{C}$, las deposiciones fueron líquidas los 10 primeros días y posteriormente normales. El peso descendió a $8.400 \mathrm{grs}$, falleciendo a los 40 días de hospitalización (18-vi-73).

\begin{tabular}{ccccc}
\hline & G. rojos & Hb $(\mathrm{gr} \%)$ & Leucocitos & Plaquetas \\
\cline { 2 - 5 } $11-\mathrm{v}-73$ & 3.900 .000 & 9,7 & 10.000 & Normales \\
$25-\mathrm{v}-73$ & 4.100 .000 & 10,0 & 11.700 & Normales \\
$1-\mathrm{vi-73}$ & 3.200 .000 & 5,9 & 12.900 & Normales \\
$11-\mathrm{v1-73}$ & 3.100 .000 & 8.0 & 12.400 & Normales \\
$18-\mathrm{vI}-73$ & 2.000 .000 & 7,1 & 2.100 & Normales \\
\hline
\end{tabular}




\begin{tabular}{lcccc} 
& $\begin{array}{c}\text { Bilirrubina } \\
\text { directa }\end{array}$ & $\begin{array}{c}\text { Bilzrnibina } \\
\text { tolal }\end{array}$ & $\%$ & $\begin{array}{c}\text { Transaminasa } \\
\text { piruivica }\end{array}$ \\
\hline $11-\mathrm{v}-73$ & $0.21 \mathrm{mg} \%$ & $1,23 \mathrm{mg} \%$ & 17 & $21 \mathrm{U}$ \\
$24-\mathrm{v}-73$ & $0,37 \mathrm{mg} \%$ & $0,75 \mathrm{mg} \%$ & 49 & 22.50 \\
\hline
\end{tabular}

Inmuglobulinas (18-v-73): IgM. está aumentado (normal: 133 a $187 \mathrm{U} / \mathrm{ml}$.), $\quad \operatorname{IgG} 158 \mathrm{U} / \mathrm{ml}$, IgM $274 \mathrm{U} / \mathrm{ml}, \mathrm{IgA} 64 \mathrm{U} / \mathrm{ml}, \mathrm{C}-3: 135 \mathrm{mg} \%$

Haptoglobina: $14 \mathrm{mg} \%$.

Alfafetoproteína positiva $1 / 64$.

Mielograma (31-v-73): normal.

Radiografía de abdomen simple: marcada hepatomegalia.

Pielografía de eliminación: lado izquierdo buen contraste, a derecha contraste muy tenue y no se observan los límites pielocaliciarios.

Proteinemia 58,1 gr \%. Orina: indicios de albúmina.

Radiografia de tórax (7-vi-73): múltiples sombras nodulares en pulmón izquierdo, mediastino desviado a izquierda.

Radiografia de cráneo normal.

La autopsia confirmó un carcinoma hepático primario con metástasis pulmonares e invasión de vena cava inferior.

\section{CASO CLINICO N ${ }^{\circ}$}

Ficha 252999: H. H. B. F. Lactante de 6 meses de edad, sexo masculino. Ingresa al Hospital Arriarán donde permaneció 21 dias hospitalizado con los diagnósticos de hemangiomatosis múltiples e insuficiencia cardiaca. Presenta desde su nacimiento hemangiomas cutáneos de tipo cavernoso que han ido aumentando en número y taman̄o. Talla $60 \mathrm{~cm}$. Peso $5.400 \mathrm{grs}$. Al examen se comprueban múltiples hemangiomas cutáneos. Se presenta disneico, hígado se palpa a $6 \mathrm{~cm}$ bajo el reborde costal y el examen cardiaco revela ligera disnea, pulsos saltones, soplo continuo sobre el hígado a nivel de la línea media grado $3 / 6$, soplo sistólico tipo vibratorio en áreas mitral grado 2/6. Bazo se palpa a $3 \mathrm{~cm}$.

Los diagnósticos de ingrem fueron: hemangiomatosis múltiple, fístula arteriovenosa hepática e insuficiencia cardíaca en tratamiento.

Durante su evolución preoperatoria que duró 37 días, se pudo apreciar aumento progresivo del hígado hasta llegar a $10 \mathrm{~cm}$ bajo el reborde costal. Permaneció con acetildigitoxina 3 gotas cada 24 horas.

Exámenes complementarios: Hemograma (22-x-7.3): Glóbulos rojos 4.400.000, Hb 10,9 grs \%, Hematocrito $34 \%$, Leucocitos 7.800 (Eos. 2, Mielo 2, Bac. 9, Seg. 19, Linfo. 52, Mono. 16). Anisocitosis. Plaquetas normales.

Estudio radiológico de tórax (29-x-73): parénquima pulmonar normal, vascularización aumentada, corazón de configuración intermedia con posible aumento de auricu- la derecha, aurícula izquierda normal, ventrículo derecho aumentado de tamaño. Ventrículo izquierdo prominente, aorta de calibre normal a izquierda, no se pudo precisar si sus latidos eran sincrónicos con la arteria pulmonar.

Protrombina $100 \%$. Uremia $0,27 \mathrm{grs} \%$.

El día $15-x I-73,16$ días después del último examen radiológico, una nueva radiografia tóracoabdominal evidencia aumento de tamaño de la sombra hepática, de la silueta cardiaca y de la circulación pulmonar.

El día 22-xI-73 se practica laparotomia: incisión transversal subcostal derecha, hígado aumentado de tamaño, superficie ccn múltiples y discretas formaciones nodulares areolares, vesícula biliar normal, bilis clara que se trasluce por sus paredes, bazo normal. Se procede a tomar muestra cuyo resultado es hemangioendotelioma benigno con cierto grado de heterotipia.

El postoperatorio se caracterizó por un estado febril de 4 dias de duración, tos y secreción purulenta de herida operatoria. Continuó con acetildigitoxina 3 gotas cada 24 horas. A los 7 dias de intervenido se inició tratamiento con prednisona $10 \mathrm{mgrs} / 24 \mathrm{hrs}$. por 3 días.

$\mathrm{Al}$ mes el hígado estaba a $6 \mathrm{~cm}$. bajo el reborde y el estado general mejoró considerablemente, por lo cual se da de alta

\section{CASO CLINICO ${ }^{\circ} 5$}

Ficha 246057: A. A. T. R. Preescolar de 2 años 3 meses de edad, sexo masculino. Ingresa al Hospital Calvo Mackenna el día 9-1v-73. Desde hace más de un año presenta aumento progresivo de volumen del abdomen.

Al examen: Regular estado general, mal estado nutritivo. Pesó 9.700 grs. Diafragmas ascendidos. Abdomen abultado, asimétrico por aumento de volumen del cuadrante superior izquierdo. Circulación venosa colateral tóracoabdominal, ombligo aplanado. A la palpación masa de 12 por $10 \mathrm{~cm}$, redondeada, abollonada, remitente que ocupa epigastrio. hipocondrio y flanco izquierdo, sobrepasa la región infraumbilical, indolora, hígado a $5 \mathrm{~cm}$. bajo el reborde costal línea medioclavicular derecha.

Al ingreso se plantearon los siguientes diagnósticos: tumor abdominal. ¿Quiste hidatídico hepático? ¿Quiste de epiplón?

Exámenes complementarios: Hemograma (9-Iv-73): eritrocitos 4.900.000, Hematocrito $38 \%$. Hemoglobina $11,8 \mathrm{grs} \%$. Leucocitos $12.900^{\circ}$ (Bar. 3, Seg. 70, Linfo. 26, Mono. 1). Plaquetas y hematies normales.

Examen de orina: albúmina 0,10 grs\%

Se interviene el día 12-IV-73: laparotomía transversal, revela masa de 20 por $15 \mathrm{~cm}$. encapsulada, pedunculada y que nace en la cara inferior del hígado, con numerosos 
vasos sanguíneos muy friables. La estructura tumoral no se continúa con el espesor del parénquima hepático. Se extrae comprobándose en el lecho hepático múltiples vasos sangrantes que se suturan consiguiendo buena hemostasia. Se cierra la cavidad aprovechando la cápsula del tumor con puntos de catgut. Puntos de lino en peritoneo.

Durante la intervención existió un periodo de shock. Se indica ampicilina por quedar bolsillo residual del tumor.

El análisis anatomohistológico de la masa tumoral demost ró tumor bien encapsulado de 18,5 por 13 por $6 \mathrm{~cm}$, que pesó $1.070 \mathrm{grs}$, al corte aspecto nodular hamartomatoso con múltiples dilataciones quísticas. Histológicamente: crecimiento desproporcionado de tejido mixomatoso. múltiples ductus biliares de variados tamaños en el espesor del estroma conjuntivo, no existen lobulillos, el epitelio de los ductus es normal, algunos dilatados otorgando aspecto quístico, hepatocitos distribuidos alrededor de estas estructuras sin constituir lobulillos. Diagnóstico: hamartoma hepático.

Evolución postoperatoria: presentó supuración de herida operatoria cuyo cultivo demostró Klebsiella enterobacter.

Se da de alta en buenas condiciones, el 23-rv-73, continuando controles en policlínica. El día 18-xu-73 pesa $10.8 \mathrm{kgrs}$, con una talla de $86 \mathrm{~cm}$, refiere dolores abdominales, al examen el abdomen es globuloso. Hemograma: 5.000 .000 de glóbulos rojos por $\mathrm{mm}$ cúbico. $\mathrm{Hb}: 12,3 \mathrm{grs} \%$. Hematocrito 39\%, 8.000 leucocitos (Bac. 4, Seg. 36, Linfo. 55, Mono. 5). VHS: $9 \mathrm{~mm}$. Hematies y plaquetas normales. Haptoglobina $135 \mathrm{mgrs}$. Inmunoglobulinas: IgG $129 \mathrm{U} / \mathrm{ml}$, IgM $181 \mathrm{U} / \mathrm{ml}$, IgA no se midió. C-3: 173 mgrs.

Evolución posterior satisfactoria, actualmente sano

\section{CASO CLINICO No6}

Ficha 184045: R. E. M. S. Lactante de 8 meses de edad, sexo masculino. Ingresa al Hospital Calvo Mackenna el día 3-Iv-69 porque la madre nota en la última semana aumento de volumen del abdomen y vómitos el día antes del ingreso.

Al examen físico se encuentra un lactante en malas condiciones nutritivas, panículo adiposo escaso, abdomen globuloso con ombligo evertido, circulación venosa colateral y matidez a la percusión abdominal, no se palpan vísceras. Diagnóstico de ingreso: desnutrición y ascitis.

Evolución: Durante los días posteriores a su ingreso persiste enorme distensión abdominal, con piel brillante y circulación colateral, tiene tránsito intestinal normal y buena tolerancia alimentaria.

Exámenes complementarios: la radiografia de abdomen simple da una imagen densa y uniforme de límites precisos que ocupa el abdomen inferior y anterior desplazando las asas intestinales hacia arriba y atrás. Radiografia de tórax: gran elevación de los diafragmas.

Orina normal. Proteinemia 54,8 grs\%.

Hernograma: 4.600.000 glóbulos rojos. Hb: 12,2 grs\%.

Hematocrito $36 \%$. 9.900 leucocitos (46 seg., 2 Bac., 2 Eos., 38 Linfo. y 9 Mono.). Discreta anisocitosis, algunos policromatófilos. Granulaciones tóxicas de los neutrófilos. Plaquetas normales.

Intervención (11-IV-69): laparotomía paramediana derecha supra e infraumbilical, se encuentra una gran tumoración quística de 1.800 grs de peso, que nace de la cara inferior del hígado inmediatamente lateral a la vesicula. Se practica enucleación del tumor aprovechando la existencia de buen plano de clivaje.

Informe anatomopatológico: 'gran masa ovoidea que mide 20 por 18 por $7 \mathrm{~cm}$, de consistencia blanda, en parte fluctuante, abollonada. Al corte está formada por quistes de gran tamaño y numerosas celdas que contienen liquido claro y tejido de aspecto gelatinoso. La pared interna de los quistes es lisa, pálida. Los tabiques están vascularizados, en ciertas zonas son más densos.

Al corte histológico hay una red más o menos dilatada de conductos biliares o hepáticos en íntima relación a grupos de células o cordones hepatocelulares, irregularmente desarrollados.

Diagnóstico: hamartoma, linfangioma hepático gigante

El 28-IV-69 (17 dias después de la intervención) es dado de alta del hospital, continuando control en Preventorio San Luis hasta el 17-vi-69.

Evolución postoperatoria satisfactoria.

\section{CASO CLINICO $\mathrm{N}^{\circ} 7$}

Ficha 233258: P. D. V. Preescolar de 2 años 1 mes de edad, sexo femenino. Ingresa el 14-vi-72 al Hospital Calvo Mackenna por cuadro respiratorio agudo con fiebre alta, tos. quejido y compromiso del estado general.

$\mathrm{Al}$ examen físico de ingreso se comprueba polipnea, retracción subcostal, espiración prolongada, submatidez en el $1 / 3$ inferior derecho del tórax, sibilancias y subcrépitos en ambas bases. En el abdomen se palpa una tumoración de límites netos, de 17 por $16 \mathrm{~cm}$, ubicada en el epígastrio e hipocondrio izquierdo, de superficie lisa, de consistencia quística, que se puede desplazar hacia los flancos, indolora.

Diagnóstico de ingreso: bronconeumonía con componente obstructivo. Desnutrición. Tumor abdominal ¿quiste?

El cuadro respiratorio agudo regresa rápidamente, recibiendo como tratamiento penicilina sódica por 10 días I. M., isopropilaminoetanol (Alupent) oral y en nebulizaciones, oxígeno húmedo en Croupette.

Exámenes complementarios: una radiografía de abdomen simple muestra una gran sombra homogénea de la mitad superior del abdomen. de más o menos 12 ó $13 \mathrm{~cm}$. que va desde región prevertebral a pared anterior del abdomen y de Fegión subdiafragmática al $3^{\circ}$ ó $4^{\circ}$ cuerpo vertebral lumbar. de límites precisos, con desplazamiento del colon transverso hacia abajo y del estómago hacia la región costodiafragmática izquierda.

El hemograma al ingreso nuestra: 3.750 .000 glóbulos rojos, $9,5 \mathrm{grs} \%$ de $\mathrm{Hb}$, hematocrito de $29 \%, 2.400$ leucocitos con $33 \mathrm{Seg} ., 4$ Bac., 1 Juvenil, 52 Linfocitos y 10 monocitos. Plaquetas normales.

Tiempo de coagulación y sangría: normales.

Orina con 0,65 grs\% de albúmina, leucocitos aislados y en placas regular cantidad.

Previa transfusión de 50 ac de glóbulos rojos para corregir anemia, se opera el 29-vi-72. practicándose una laparotomia transversal supraumbilical encontrándose un gran tumor que compromete todo el lóbulo izquierdo del higado, redondeado con cápsula, sn adherencias ! sótido. Se prarticó resección del lóbulo izquierdo del hígado. El tumor pesó $920 \mathrm{grs}$ 
Informe anatomohistológico: se examina masa redondeada de $14 \mathrm{~cm}$ de diámetro por 6 de alto. Cápsula fibrosa, consistencia firme. Al corte estructura hepática con zonas de necrosis y hemorragia. Los cortes histológicos muestran células hepáticas poliédricas con citoplasma claro, transparente y núcleo redondo central. No se observan espacios sinusoidales ni formaciones lobulillares.

En una muestra hay proliferación de conductillos biliares y cèlulas hepáticas que adoptan disposición cordonal.

Diagnóstico: tumor primitivo del hígado. Adenoma.

Exámenes postoperatorios: batería inmunológica (7-vII72): IgG $108 \mathrm{U} / \mathrm{ml}$, IgM $140 \mathrm{U} / \mathrm{ml}$, IgA $32 \mathrm{U} / \mathrm{ml}$, Haptoglobinas: $270 \mathrm{grs} \%$.

27-viIl-72: IgG $122 \mathrm{U} / \mathrm{ml}, \operatorname{IgM} 196 \mathrm{U} / \mathrm{ml}, \operatorname{IgA} 370$ $\mathrm{U} / \mathrm{ml}$, Haptoglobinas: $170 \mathrm{mgrs} \%$.

23-xI-72: IgG $152 \mathrm{U} / \mathrm{ml}, \operatorname{IgM} 192 \mathrm{U} / \mathrm{ml}, \operatorname{IgA}, 62 \mathrm{U} /$ $\mathrm{ml}$, Haptoglobinas: $200 \mathrm{mgrs} \%$.

Alfaletoproteína: negativa (7-vir-72).

Antígeno Australia: negativo en tres determinacio nes.

A los 11 días de la intervención es dada de alta en buenas condiciones. Ultimo control en Policlínica de Oncología, el 22 de noviembre de 1972.

\section{COMENTARIO}

Los tumores malignos primitivos del hígado son poco frecuentes en Pediatría. Comprometen de preferencia a niños menores de 3 años ${ }^{*}$. En nuestro material disponemos de 3 hepatoblastomas cuyas edades fueron: 1 año 4 meses, 3 años 5 meses y 2 años 5 meses. Esta patología es más frecuente en adultos sobre 50 años. Se postulan diversas etiologías basadas en la mayor incidencia, encontrada en Africa y Asia ${ }^{24}$, habiéndose demostrado asociación entre contenido de alfatoxina en los alimentos y la presentación de hepatoblastema ${ }^{3}$, esta sustancia es un metabolito del grupo Aspergillus flavus, y es el más potente hepatocarcinógeno conocido. Otros factores etiológicos mencionados ${ }^{24}$ son la constante irritación de las células hepáticas por causas quimicas, parasitarias (zoonosis) y regímenes dietéticos mal balanceados. Se agrega etiologías virales y de remanentes embrionarios ${ }^{26}$. Yoshida sostiene que ciertos factores tintoriales inducen formación de cáncer primitivo, en ratas.

En los tres casos relatados es posible observar que el niño de 1 año 4 meses presentó un comienzo insidioso: 9 meses antes de la consulta, aumento progresivo abdominal; actualmente está vivo. El paciente de 3 años 5 meses, comienzo brusco con dolores cólicos y vómitos; fallece a los 4 meses de operado. El caso $\mathrm{N}^{\circ} 3$, de 2 años 5 meses de edad, el único de sexo femenino, tambiên presentó comienzo brusco con fiebre, tos, disnea y meteorismo; al examen de ingreso se encuentra resistencia abdominal y dolor a la palpación. Se planteó el diagnóstico de abdomen agudo. Al mes de intervenido, fallece.

De gran utildad diagnóstica para los casos de tumores malignos del hígado es la alfafetoproteína $^{2-9-19}$ en el suero. Fue descrita por Bergstrand y Czar en fetos de 9 a 19 semanas, como una proteína especial que migra en la electroforesis en papel entre la albúmina y la alfa-1 globulina.

En 1963, Abelev la describió en hepatomas experimentales en ratas, y estudios posteriores en clínica humana la describen como alfaglobulina embrioespecífica en el suero de pacientes con carcinoma hepático y teratomás malignos de otros órganos. En dos de nuestros pacientes se practicó dicho examen, y fue positivo; en uno no se efectuó. Cuando el tumor es extirpado totalmente, como en el caso $\mathrm{N}^{\circ} 1$, el nivel de alfafetoproteína tiende a declinar y a desaparecer.

Según algunos autores ${ }^{19}$, la determinación de Alfa-1-fetoproteínas es el examen de laboratorio más sensible para evaluar el efecto de la quimioterapia en los hepatoblastomas.

Las medidas terapéuticas con las cuales se cuenta en la actualidad en los tumores primitivos malignos del hígado son la cirugía si el tumor está limitado a un lóbulo como en el caso $\mathrm{N}^{\circ} 1$, asociada a quimioterapia (Vincristina, Ciclofosfamida y Actinomicina D) en dosis semanal. En la eventualidad que las masas tumorales comprometen a todo el parénquima hepático correspondiendo al tipo III de Holton ${ }^{11}$, la cirugia es imposible al igual que en los casos en los cuales hay metástasis por extensión directa a vísceras adyacentes o metástasis a distancia. En estos grados el pronóstico es malo y está indicada exclusivamente la quimioterapia con Vincristina $1,5 \mathrm{mg} / \mathrm{m}^{2}$ I. V., semanalmente, Ciclofosfamida $300 \mathrm{mg} / \mathrm{m}^{2}$ seis semanas, y j-FU $300 \mathrm{mg} / \mathrm{m}^{2}$ dos semanas, dos años.

Según Holton y col. la Adriamicina la reserva para aquellos casos en que existe progresión tumoral.

El resultado del tratamiento quimioterápico es pobre en estos tumores. Según nuestra experiencia estaría determinado por varios factores, entre los que destacamos: 1) el grado clínico, 
siendo de mejor pronóstico aquel tipo unicéntrico, con lesión lobar de menos de $5 \mathrm{~cm}$, totalmente resecable como el caso $\mathrm{N}^{\circ} 1$, y de peor pronóstico el tipo IV con metástasis a distancia; 2) el estado nutritivo e inmunitario del huésped; 3) el tipo histológico del tumor, su vascularización, su tendencia necrótica y su delimitación; 4) finalmente debemos descatar que el resultado de la quimioterapia depende de la resistencia de la célula tumoral a la droga. Las células que permanecen en etapa Go latente son resistentes a la quimioterapia, ya que ésta actúa en la fase de síntesis y duplicación cromosómica.

En vista de estos factores proponemos combinación de drogas y las dosis totales utilizadas son las máximas tolerables.

Se insiste en la labor importantísima que tiene el pediatra general en la pesquisa de tumores en etapas clínicas incipientes y su rápido envío a un Centro Oncológico especializado.

Hasta antes de $1970^{11}$ no existía sobrevida en un grupo de 20 niños con tumores hepáticos malignos. Los tratamientos eran diversos.

Actualmente podemos demostrar buen resultado en uno de los tres casos de hepatoblastoma presentados y es precisamente aquel que fue extirpado totalmente.

En la literatura se recomienda - al hacer la intervención - la ligadura de la arteria hepáti$\mathrm{ca}^{1}$ y previa a la operación una angiografía ${ }^{5}$.

En el Caso $N^{\circ} 1$ la quimioterapia fue suspendida a los 8 meses de operado, considerándose de buen pronóstico, debido a que mediante la intervención quirúrgica se extirpó tołalmente el tumor; en cambio en los casos 2 y 3 se procedió a obtener material para biopsia siendo imposible extirpar el tumor por tener distribución múltiple.

El caso $\mathrm{N}^{\circ} 4$ corresponde a hemangioendotelioma y reúne todos los requisitos diagnósticos que se han descrito: hepatomegalia, hemangiomatosis múltiple e insuficiencia cardiaca, a lo que se agrega además un soplo continuo en el área hepática ${ }^{6-7-8-10-12-21-23}$.

Existía el antecedente de que las lesiones hemangiomatosas de la piel habían ido aumentando progresivamente de tamaño desde su nacimiento, apareciendo insuficiencia cardiaca. En general esta afección es rara en recién nacidos y lactantes ${ }^{6}$ : algunos tienen pronósti$\cos$ favorables por la evolución natural que tienen este tipo de tumores. Algunos autores ${ }^{6-12}$ diferencian el hemangioendotelioma $y$ en hemangiomas cavernosos con mayor compromiso arteriolar y venoso. Ambas formas se caracterizan por presentar idéntica sintomatología cuando comprometen el hígado.

Este tipo tumoral es derivado del mesodermo, es de carácter benigno y para él se han propuesto varios tratamientos.

Si el tumor se acompaña, como en el caso analizado, de insuficiencia cardiaca, el tratamiento se limita a esta última. No debe efectuarse en estos casos biopsia por punción. Según $\mathrm{P}$. Braun $^{6}$ el riesgo de muerte por lobectomía sería de un $22 \%$, sin embargo la operación debe ser efectuada en caso de hemorragia masiva ${ }^{7-10}$. El riesgo de ruptura es mayor en hemangiomas que en adenomas ${ }^{21}$. Los ascensos y descensos de la presión determinan aumento de la fragilidad capilar: se han descrito rupturas espontáneas al descender de un avión.

El segundo enfoque terapéutico propiciado es el uso de corticoesteroides ${ }^{6}$. Según Fost $^{8}$ tiene resultados buenos al usar prednisona en 6 casos con regresión del hemangioma en cinco. Los esquemas propuestos por este autor son dosis de $30 \mathrm{mgrs} / 24 \mathrm{hrs}$. por 2 semanas, o 20 mgrs diarios por 4 semanas. La acción del cortocoide no está clara y determinaría una proliferación de células endoteliales que obliterarían el lumen capilar. Al respecto no tenemos experiencias.

También se ha propuesto radioterapia postoperatoria ${ }^{12}$.

Los casos $N^{o s} 5,6$ y 7 corresponden a tumores que por sus caracteres histológicos son considerados también como benignos. Han recibido varios términos descriptivos como "hepatoma benigno", "colangiohepatoma hamartomatoso" y "hamartoma", terminología que, a nueştro parecer, ha agregado más confusión en su clasificación

Se define como hamartoma una malformación seudotumoral caracterizada por una relativa desproporción de los variados componentes normales tisulares que conforman un órgano. Del análisis crítico de dicha definición" surge la interrogante de poder clasificar $y$ diferenciar hamartomas $y$ adenomas hepáticos.

Los términos tan variados enunciados anteriormente fueron propuestos para describir 
tumores benignos que hoy clasificamos como adenomas. La diferenciación sería arbitraria en general por los caracteres histológicos ${ }^{4-15}$ y por su ubicación, ya que el adenoma es intraparenquimatoso y el hamartoma es superficial. Creemos que es conveniente continuar definiendo el adenoma como un tumor de origen epitelial benigno con escasa des viación de la estructura normal del hígado ${ }^{24}$ medida por la determinación de DNA.

En estos tres casos el volumen tumoral fue mucho mayor que en los tumores malignos del hígado. Los casos $N^{\text {os }} 5$ y 6 , que correspondieron a hamartoma pesaron, respectivamente, 1.070 y $1.800 \mathrm{grs}$ y el adenoma (caso $\mathrm{N}^{\circ} 7$ ) pesó 920 grs. Por su crecimiento y pese a no existir anaplasia celular son considerados como verdaderos tumores. Estos tumores evolucionan lenta y progresivamente siendo muchas veces asintomáticos por largos períodos, mostrando como único hecho positivo un abdomen prominente.

Según algunos autores ${ }^{16 \cdot 17 \cdot 20 \cdot 21 \cdot 22 \cdot 25}$ se distinguen adenomas de células hepáticas y adenomas de vías biliares, los primeros son de mayor tamaño y se encuentran en el parénquima hepático, confundiéndose con él; los otros son más pequeños, encapsulados y de color blanco amarillento.

Estos últimos son más frecuentes en mujeres adultas, y se caracterizan por presentar ictericia de tipo obstructivo y por consiguiente son hallazgos de la cirugía biliar.

Los 4 casos de tumores benignos analizados tuvieron buen pronóstico. Damos la mayor importancia al hecho de continuar estrictos controles sobre todo en los que se han hecho el diagnóstico de adenoma ya que es posible la existencia de cierto grado de atipia celular que lo transformaría en tumor maligno.

La cirugía es el método terapéutico único en adenomas, hamartomas y en tumores malignos de grado clínico $\mathrm{I}$.

\section{REFERENCIAS}

1 Kotudahl, $G$. and Funding, $J$. Hepatic artery ligation in primary and secondary cancer. Acta Chir. Scandinav 138:289-a92, 1972.

2 Alper, E.; Starzl, T.; Schur, P. and Iselbacher, $K$ Serum alphafeto-protein in hepatoma patients after liver transplantation. Gastroenterology 61: 144-148, Aug. 1971.
Alpert, M. E. Hutt, M. S. R.; Wogan, G. N and Davitson, C. S. Association between aflatoxin content of foot and hepatoma frecuency in Uganda. Cancer 28:253-260, July 1971.

4 Keeling, J. W'. Liver tumor in infancy and Childhood J. of Pathology 193: 69-85, 1971

s Kido, Ch.; Sasaki, T. and Keneko, M. Angiography of primary liver cancer. Am. J. Roentgenol. 11.3: 70-81, Sept. 1971

B Braun, P.; Ducharme, J.C.; Rropelle, J.L. and Darngnon, 1. Hemangiomatosis of the liver in infants. J. of Ped. Surgery $19(1)$ : 121-126, Feb. 1975.

7 Stone, H. H. Major hepatic resection in children. J. of Ped. Surgery 19(1): 127-134, Feb. 1975.

- Fost, A. C. and Esterly, N.B. Successful treatment of juvenile hemangioma with prednisone. Journal of Pediatrics 72 (3):351-357, March 1968.

- Houstek, J.; Masopust, J.; Kuther, K. and Rade, J. Hepatocellular carcinoma in association with a specific fetal alpfa-1-globulin, fetoprotein. The J. of Ped. 72 (2): 186-193, Feb. 1968.

10 Lilloa, I. Segmentectomía lateral izquierda del hígado por hemangioma en un niño de 3 meses de edad Especial referencia a la segmentación hepática y su importancia en cirugía. Rev. Chil. de Pediatría 39:547. $553,1968$.

1 Holton, Ch. P.; Burrington, J. D. and Hatch, E. I. A multiple chemotherapeutic approach to the managment of hepatoblastoma. Cancer 35:1083-1087, April 1975

12 Dehner, I. P. and Ishak, K. G. Vascular tumors of the liver infants and children. Arch. of Pathol. 92:101-110, Aug. 1971

13 Sherlock, $S$. Enfermedades del hígado y del sistema biliar, 1967

14 Garancís. J. C. and Tang. T. Hepatic Adenoma. Cancer 24:560-568, Sept. 1969 .

10 Opitz, H. y Schmid, F. Tumores en la infancia, Enciclopedia pediátrica. pág. 486, 1974

16 Thompson, J.E. and Wolff, M. Intrahepatic Cystoadenoma of bile duct origin, with malignant alteration. Report of a case, treated with total left hepatic lobectomy. Military Med. 218-224, March 1965.

17 Snedecor, P.A. Bile duct Cystoadenoma of the liver Ann. of Surgery $3.3(7): 581-583$, July 1967.

is McIntyre, J.A. and Pay-Zen, Cheng. Adenoma of the common bile duct causing obstructive jaudice The canad. J. of Surgey 11:215-218, April 1968

19 Matiumoto, Y.; Suzuki, T.: Ono, H.; Vakse, A. and Honjo, I. Response of alphafetoprotein to the chemoterapy in patients with hepatoma. Cancer $34: 1602$ 1606, Nov. 1974.

20 Sommelel, $J$. et Bessot, .4. Les tumeurs benignes des voies biliaires extrahepatiques. J. Chir. (Paris) gl) (4): 321-328, Oct. 1965.

21 Scorer, C. G. Spontaneous rupture of a hepatic adenoma Brit J. Surgery 56-8:633-635, 1969.

22 Inui, N.; Takayama, $S$. and Kuwabarn, $N$. DNA messurement on cellnnucleus of normal liver, adenoma and hepatoma in mice: histologic features. J. of the Nat. Cancer Inst. 47:47-58, 1971. 
23 Asch, M. J.; Cohen, A. H. and Moore, T. C. Hepatic and splenic lymphagiomatosis with skeletal involvement: report of a case an review of the literature. Surgery 76 (2): 334-339, Aug. 1974.
24 Titelman, J.; Estérez, R. y Rojas, J. Tumores primitivos del hígado o hepatomas. Arch. Soc. Cir. de Chile 24 (1) :271-275, marzo 1972.

2s Robbins S.L. Patología estructural y funcional. primera edición, pág. 983,1975. 